\title{
Characterization of Genetic Components Involved in Durable Resistance to Stripe Rust in the Bread Wheat 'Renan'
}

\author{
F. Dedryver, S. Paillard, S. Mallard, O. Robert, M. Trottet, S. Nègre, G. Verplancke, and J. Jahier
}

First, second, third, fifth, sixth, seventh, and eighth authors: INRA UMR 118 Amélioration des Plantes et Biotechnologies Végétales, Domaine de la Motte, BP35327, 35653 Le Rheu cedex, France; and fourth author: Bioplante, 60 rue Léon Beauchamp, 59933 La Chapelle d'Armentières, France.

Accepted for publication 2 April 2009.

\begin{abstract}
Dedryver, F., Paillard, S., Mallard, S., Robert, O., Trottet, M., Nègre, S., Verplancke, G., and Jahier, J. 2009. Characterization of genetic components involved in durable resistance to stripe rust in the bread wheat 'Renan'. Phytopathology 99:968-973.

Stripe rust, caused by Puccinia striiformis f. tritici, is one of the most widespread and destructive wheat diseases in areas where cool temperatures prevail. The wheat $\mathrm{cv}$. Renan, carrying the specific gene $\operatorname{Yr17}$, has shown effective resistance for a long time, even though some pathotypes overcame the $\operatorname{Yr} 17$ gene. The objectives of this study were to locate and map genetic loci associated with adult-plant resistance (APR) to stripe rust in a recombinant inbred line population derived from a cross between

for 4 years $(1995,1996,2005$, and 2006) to score disease-progress data and identify APR quantitative trait loci (QTLs). Three QTLs, QYrinra$2 B S$, QYrinra-3BS, and QYrinra-6B, with resistance alleles derived from Renan were detected in 1995 to 1996 with the 237E141 pathotype, which is avirulent against genotypes carrying $\mathrm{Yr} 17$. These QTLs were stable and explained a major part of the phenotypic variation seen in 2005 to 2006, when the 237E141 V17 pathotype was used. Each of these QTLs contributed $\approx 4$ to $15 \%$ of the phenotypic variance and was effective at different adult plant stages. Interactions were observed between some markers of the $\operatorname{Yr} 17$ gene and three Renan QTLs: QYrinra-2BS, QYrinra-3BS, and QYrinra-6B. Resistance based on the combination of different APR types should provide durable resistance to P. striiformis.
\end{abstract} Renan (resistant) and Récital (susceptible). Field assays were performed
Stripe rust, caused by Puccinia striiformis f. tritici Eriks., is a major disease of wheat (Triticum aestivum L.) in cool and humid production regions (40). In most wheat-producing areas, yield losses caused by stripe rust are 10 to $70 \%$ depending on the susceptibility of the cultivar, earliness of the initial infection, rate of disease development, and duration of disease (7). The use of resistant cultivars is the most effective, economical, and environmentally friendly means to control stripe rust.

Resistance to stripe rust can be categorized as all-stage resistance (also known as seedling resistance [SR]), which can be detected at the seedling stage but is also expressed at all stages of plant growth, or as adult-plant resistance (APR), expressed at later stages of plant growth (7). Seventy validated and tentative resistance genes, designated $Y r$, were reported by Chen (7) and McIntosh et al. (28). Seedling resistance is generally qualitatively inherited, race-specific, and, thus, easily overcome by new virulent races of the rust fungus (19). Although this may also be the case for APR genes (21), adult plant resistance is generally quantitatively inherited, non-race-specific, and durable $(7,20)$. The identification and use of these sources of resistance, which are not matched by single virulence alleles, in breeding programs should lead to an increase in the durability of disease control via host resistance (17).

The present work describes the genetic analysis of APR to stripe rust in the bread wheat cv. Renan, which has shown effective resistance for a long period of time (1989 to date) in an environment favorable to stripe rust epidemics. The $\operatorname{Yr} 17$ resistance gene is a major source of resistance in Renan, and it was

Corresponding author: F. Dedryver;

E-mail address: francoise.dedryver@rennes.inra.fr

doi:10.1094/PHYTO-99-8-0968

(C) 2009 The American Phytopathological Society introgressed by Maia from Aegilops ventricosa accession 10 $(1,25)$ into the wheat line VPM1, a parent of Renan. The $\operatorname{Yr} 17$ resistance gene was overcome in the United Kingdom in 1994 (4) and in France in 1998 (32). The objective of this study was to identify the genes conferring different APR types of stripe rust resistance in Renan through quantitative trait loci (QTLs) analyses. We did this by analyzing the disease severity of stripe rust on wheat lines on three occasions after each rust cycle and by calculating the area under the disease progress curve (AUDPC). We compared the results from both types of analysis to estimate the maximum number of APR components.

\section{MATERIALS AND METHODS}

Plant materials. A mapping population of $194\left(\mathrm{~F}_{6}\right.$ and $\left.\mathrm{F}_{7}\right)$ recombinant inbred lines (RILs) was developed by single-seed descent from the cross between two winter bread wheat cultivars, Renan and Récital. Renan is a resistant cultivar derived from the cross Mironovskaia 808/Maris Hunstman//VPM Moisson 4/ Courtot. Récital is a susceptible French cultivar derived from the cross Mexique 267/5/(81.12/Besostaya 1//Heines VII/3/Nord/4/ Tadorna), 9369. The SR genes identified in Récital and Renan were $\operatorname{Yr} 6$ (11) and $Y r 2, Y r 3, Y r 17$, and $S D$, respectively (30).

Field trials and field assessment of resistance. RILs and their parents were evaluated in the field at the INRA experimental farm in Le Rheu (Rennes-35, France). The field was $>1 \mathrm{~km}$ from the nearest wheat crop. Evaluations were performed in 1995 and 1996 with the $P$. striiformis f. tritici 237E141 pathotype, which possesses virulence to $Y r 1, Y r 2, Y r 3 a, Y r 4 a, Y r 6, Y r 9, Y r S D$, and $Y r S U$; and in 2005 and 2006 with the 237E141 V17 pathotype, which contains the additional virulence to $\operatorname{Yrl7}$ (3) and overcomes all SR genes of Renan and Récital. In every experiment, 12 seeds from each line were sown in a row at the end of October and arranged in a completely randomized block design, with two 
replicates in 1995 and 1996 and only one replicate in 2005 and 2006. Cv. Récital was planted in every third row as a susceptible spreader of disease. Additionally, seedlings cultivated in a growth chamber to the two-leaf stage were artificially inoculated with $P$. striiformis f. tritici. Plants were reared at 6 to $10^{\circ} \mathrm{C}$ in a growth chamber with a photoperiod of 10 and $14 \mathrm{~h}$ (light and darkness, respectively) until leaves were totally covered by stripe rust pustules, and then transplanted to the experimental plot. To ensure a high level of disease pressure, two or three inoculated plants were planted in $30 \%$ of Récital rows during November, January, February, and early March of each year.

Stripe rust scores were recorded on three separate occasions: at the time of rust appearance (N1), corresponding to the growth stage DC32 (41), and after each cycle of pathogen multiplication on the susceptible parent Récital (N2 and N3), with N2 corresponding to the growth stage DC39 and N3 to the grain-filling stage DC79 of Récital. The scoring method, using a 0 to 12 scale (Table 1), and the estimation of the AUDPC were as described by Mallard et al. (26). At the end of each experiment, rusted leaves were randomly collected in the experimental field. Differential hosts were inoculated with the collected spores to confirm the identity of the 237E141 and 237E141 V17 pathotypes, using seedling-stage assessment as described by Mallard et al. (26).

Statistical analysis. Replicate or year and genotype effects were tested by analysis of variance (ANOVA) with the PROC GLM procedure of the SAS statistics package (SAS Institute, Raleigh, NC). The homogeneity of phenotypic variance between replicates or years and genotypes was verified using Bartlett's test, and the normality of residual distributions was checked using the PROC UNIVARIATE procedure. Within each year (1995 or 1996), broad-sense heritability was estimated from the ANOVA using the formula: $h^{2}=\sigma_{\mathrm{G}}{ }^{2} /\left[\sigma_{\mathrm{G}}{ }^{2}+\left(\sigma_{\mathrm{e}}{ }^{2} / r\right)\right]$, and over the years (1995 to 1996 and 2005 to 2006) using the formula $h^{2}=\sigma_{\mathrm{G}}{ }^{2} /\left[\sigma_{\mathrm{G}}{ }^{2}+\right.$ $\left.\left(\sigma_{\mathrm{e}}^{2} / E\right)\right]$, where $\sigma_{\mathrm{G}}^{2}=$ the genetic variance, $\sigma_{\mathrm{e}}^{2}=$ the residual variance, $r=$ the number of replicates per line, and $E=$ the number of environments (years). Year and within-year replicates were both considered to be classical replicates, which likely led to an underestimate of heritability. For all tests, a probability level of $P<0.05$ was considered significant.

Map construction. A genetic linkage map constructed during a Génoplante project $(14,15)$ using 182 restriction fragment length polymorphism (RFLPs) loci, 258 simple sequence repeat (SSR) markers, and 68 amplified fragment length polymorphism (AFLP) loci has been used in this study. Additionally, a SCAR marker of Yrl7 gene SC-Y15 described by Robert et al. (31) was mapped in this study. Fresh leaves from parents and individual RIL plants were ground in liquid nitrogen. DNA was extracted from the leaf powder using the cetyltrimethylammonium bromide (CTAB) method (34). DNA was quantified using a spectrofluorometer (Spectra max M2; Molecular Devices, Sunnyvale, CA). The SSR analysis was conducted following Röder et al. (33). The RFLP and SCAR analyses were performed as described by Robert et al. (41). The AFLP analysis was conducted essentially according to Vos et al. (39) and following the protocol of Mallard et al. (27). Linkage analysis was performed with the MAPMAKER/EXP package, version $3.1(23,24)$. Genetic distances were calculated using the Haldane mapping function (16). Linkage groups were assigned to chromosomes by comparison with the International Triticeae Mapping Initiative (ITMI) map (33). The Renan/Récital (ReR) map was composed of 34 linkage groups and covered 2,259.6 centimorgans $(\mathrm{cM})$.

QTL analysis. QTL detection was carried out by composite interval mapping (CIM) $(42,43)$ using QTL CARTOGRAPHER software, version 2.5 (2). A forward-backward stepwise regression was performed to choose cofactors before QTL detection by CIM. Ten cofactors with the highest $F$ value were taken into account. A window size of $10 \mathrm{cM}$ around the test interval was chosen for all analyses. Permutation tests were carried out to identify the appropriate significant logarithm of odds (LOD) thresholds for each trait to identify a QTL. After 1,000 permutations and following the analyzed traits, critical LOD thresholds were set from LOD > 3.3 to LOD > 3.5. The QTL-QTL interactions and percentage of phenotypic variation explained by the whole model (total $R^{2}$ ) were determined using multiple interval mapping (MIM). For MIM analysis, the QTL peaks with the critical LOD thresholds from the CIM analysis were used as the initial model. New QTLs were added to the current model. The proportion of phenotypic variation explained by individual QTL and by the whole model (total $R^{2}$ ), the additive and dominant effects, and the QTL-QTL interaction were estimated using the 'summary' option of MIM.

\section{RESULTS}

Phenotypic assessment of stripe rust infection. The analysis of spores collected at the end of each experiment revealed that no contamination by other pathotypes than the one used for inoculation occurred during the growing season. The frequency distribution for the AUDPC in all four trials was continuous (Fig. 1). In 1995 and 1996, the experiments were conducted with the 237E141 pathotype and all Renan parent plants were resistant. With the 237E141 V17 pathotype (2005 and 2006 experiments), which overcomes $\mathrm{Yr} 17$ conferred resistance, a slight infection occurred on Renan only for the N1 scoring in 2006 (score = 2), which was a year with a very strong epidemic. Renan displayed a low AUDPC of 20 in 2006, whereas the susceptible parent Récital showed a maximum AUDPC of 333 and 437 in 2005 and 2006, respectively. Within-year and over-years heritability values for the AUDPC were high (Table 2). ANOVA (Table 2) showed significant genotype effects for the AUDPC within each year (1995 and 1996) and over years (1995 to 1996 and 2005 to 2006). A replicate effect for the AUDPC was significant only in 1996 (Table 2). In that year, AUDPCs were higher in the first replicate (mean = $114.5)$ than in the second replicate $($ mean $=104.5)$. A slight year effect was observed for the experiments conducted with the 237E141 pathotype (1995 to 1996). A large year effect was significant for the experiments conducted with the 237E141 V17 pathotype (2005 to 2006). In 2005, the AUDPC mean was lower (113.8) than in 2006 (162.7). High levels of correlation were observed between replicates (0.83 in 1995 and 0.89 in 1996) and between years ( 0.90 for 1995 to 1996 and 0.83 for 2005 to 2006). Consequently, for each pathotype, we used year effect as replicate.

QTL analysis of the disease-progress data. For each pathotype, QTL analysis was carried out for the three stripe rust scorings $(\mathrm{N} 1, \mathrm{~N} 2$, and N3) made at the time of rust appearance and after each cycle of pathogen multiplication on the susceptible parent Récital. For the 1995 to 1996 assessments, based on the used pathotype's avirulence to Yr17, six QTLs with additive effects were detected (Table 3). Four of these QTLs were identified for all scorings. These four QTLs were localized on chromosomes 2AS, 2AL, 2BS, and 3DS. For the QTL QYrinra-2AS2, the proportion of phenotypic variance observed was large and depended on the scoring data. The resistance was conferred by $A$. ventricosa 10 alleles, found within the $\operatorname{Yr} 17-\operatorname{Lr} 37-S r 38$ translocation into the Xgwm512-Xgwm400b interval of the resistant

TABLE 1. Scale used for stripe rust ratings at the adult plant stages

\begin{tabular}{|c|c|c|c|c|c|c|c|c|c|c|c|c|c|}
\hline Leaf area affected by disease $(\%)$ & 0 & 0.3 & 0.7 & 2 & 8 & 12 & 16 & 24 & 33 & 50 & 66 & 82 & 100 \\
\hline Scale & 0 & 1 & 2 & 3 & 4 & 5 & 6 & 7 & 8 & 9 & 10 & 11 & 12 \\
\hline
\end{tabular}


parent Renan. QYr.inra-2BS explained 8.79 to $12.29 \%$ of the phenotypic variation, depending on the scoring. The resistance was conferred by a Renan allele. Another QTL, QYrinra-3DS, associated with a Récital allele, was located on chromosome 3D and explained a small proportion of the phenotypic variation. The QTL QYr.inra-2AL, with minor effects, was identified on the long arm of chromosome $2 \mathrm{~A}$ and the resistance allele was contributed by Récital. Two other QTLs, QYrinra-3BS and QYrinra-6B, found on chromosomes $3 \mathrm{~B}$ and $6 \mathrm{~B}$, respectively, were detected only for one or two scorings.

The 237E141 V17 pathotype, which overcomes resistance conferred by $\operatorname{Yr} 17$, was used in the 2005 to 2006 assessments: eight QTLs with additive effects were detected (Table 3). The QTL associated with the introgression of $A$. ventricosa into the Renan chromosome 2AS was no longer detected. However, one QTL with resistance allele contributed by Récital, QYrinra-2AS1, was located in wheat region 2AS which is homeologous to the $\mathrm{Yr} 17$ introgression (A. ventricosa segment $2 \mathrm{~N}^{\mathrm{v}}$ ). This QTL, with minor effects, was identified in two scorings: N2 and N3. The QYr.inra2BS, QYrinra-3BS, and QYrinra-6B QTLs, with resistance alleles derived from Renan and previously detected in 1995 to 1996 , were stable and explained a major proportion of the phenotypic variation in 2005 to 2006 (Fig. 2). The expression of the QYrinra$3 D S$ QTL, associated with a Récital allele, was also consistent over the 4 years. Based on the 2005 to 2006 data, three new QTLs were also identified. QYrinra-1A and QYrinra-3Bcent, with resistance alleles conferred by Renan, were detected only for one or two scorings, respectively (N3 and N1-N2). QYr.inra-7A was only identified for the N1 scoring. The resistance for this QTL was conferred by Récital. ANOVA results confirmed that all markers included within the QTL intervals were highly significant $(P<0.001)$.

QTL analysis of the AUDPC. The QTLs detected by analysis of the AUDPC were compared with those identified by analysis of the scoring data: N1, N2, and N3 (Table 3). QTL analysis of the AUDPC for 1995 to 1996 led to the identification of five of the six QTLs identified from the scoring data: QYrinra-2AS2, QYrinra-2AL, QYr.inra-2BS, QYr.inra-3DS, and QYr.inra-6B. The
QTL QYrinra-3BS, which was associated with the N3 scoring, was not identified. When the AUDPC for 2005 to 2006 was analyzed, none of the QTLs which were previously detected for only one scoring (QYr.inra-1A, QYr.inra-3BS, and QYr.inra-7A) were identified. However, the QYrinra-2AS1, QYr.inra- $2 B S$, QYrinra-3Bcent, QYrinra-3DS, and QYrinra-6B QTLs were detected by the two analysis methods.

The epistatic effects of QTLs were also evaluated using MIM analysis and showed that some interactions between different QTLs were significant. In 1995 to 1996, significant interactions were determined between either XSC-Y15 or Xgwm400, markers of the A. ventricosa introgression into the $2 \mathrm{AS}$ chromosome of wheat, and one of the following QTLs: QYrinra-2AL, QYrinra$2 B S$, QYr.inra-3DS, and QYr.inra-6B. These interactions ex-

TABLE 2. Analysis of variance of genotype, replicate or year effects for the area under the disease progress curve, and the proportion of phenotypic variation for stripe rust intensity among recombinant-inbred lines developed from a cross between Renan and Récital wheat cultivars

\begin{tabular}{lrccc}
\hline Year & MS $^{\mathrm{a}}$ & $F$ value & $P$ value & $h^{2}$ \\
\hline 1995 & & & & \\
Genotypes & 26,756 & 21.86 & $<0.0001$ & $0.95^{\mathrm{b}}$ \\
Replicates & 3 & 0 & 0.9602 & $\ldots$ \\
Error & 1,224 & $\ldots$ & $\ldots$ & $\ldots$ \\
1996 & & & & \\
Genotypes & 21,578 & 31.02 & $<0.0001$ & $0.96^{\mathrm{b}}$ \\
Replicates & 8,976 & 12.90 & 0.0004 & $\ldots$ \\
Error & 696 & $\ldots$ & $\ldots$ & $\ldots$ \\
1995-1996 & & & & \\
Genotypes & 45,934 & 39.96 & $<0.0001$ & $0.97^{\mathrm{c}}$ \\
Years & 6,363 & 5.54 & 0.0190 & $\ldots$ \\
Error & 1,149 & $\ldots$ & $\ldots$ & $\ldots$ \\
2005-2006 & & & & \\
Genotypes & 30,176 & 15.12 & $<0.0001$ & $0.93^{\mathrm{c}}$ \\
Years & 223,902 & 112.17 & $<0.0001$ & $\ldots$ \\
Error & 1,996 & $\ldots$ & $\ldots$ & $\ldots$ \\
\hline
\end{tabular}

a MS = mean square.

b Broad-sense heritability $\left(h^{2}\right)$ computed using replicates within year.

c Broad-sense heritability $\left(h^{2}\right)$ computed using year as replicate.
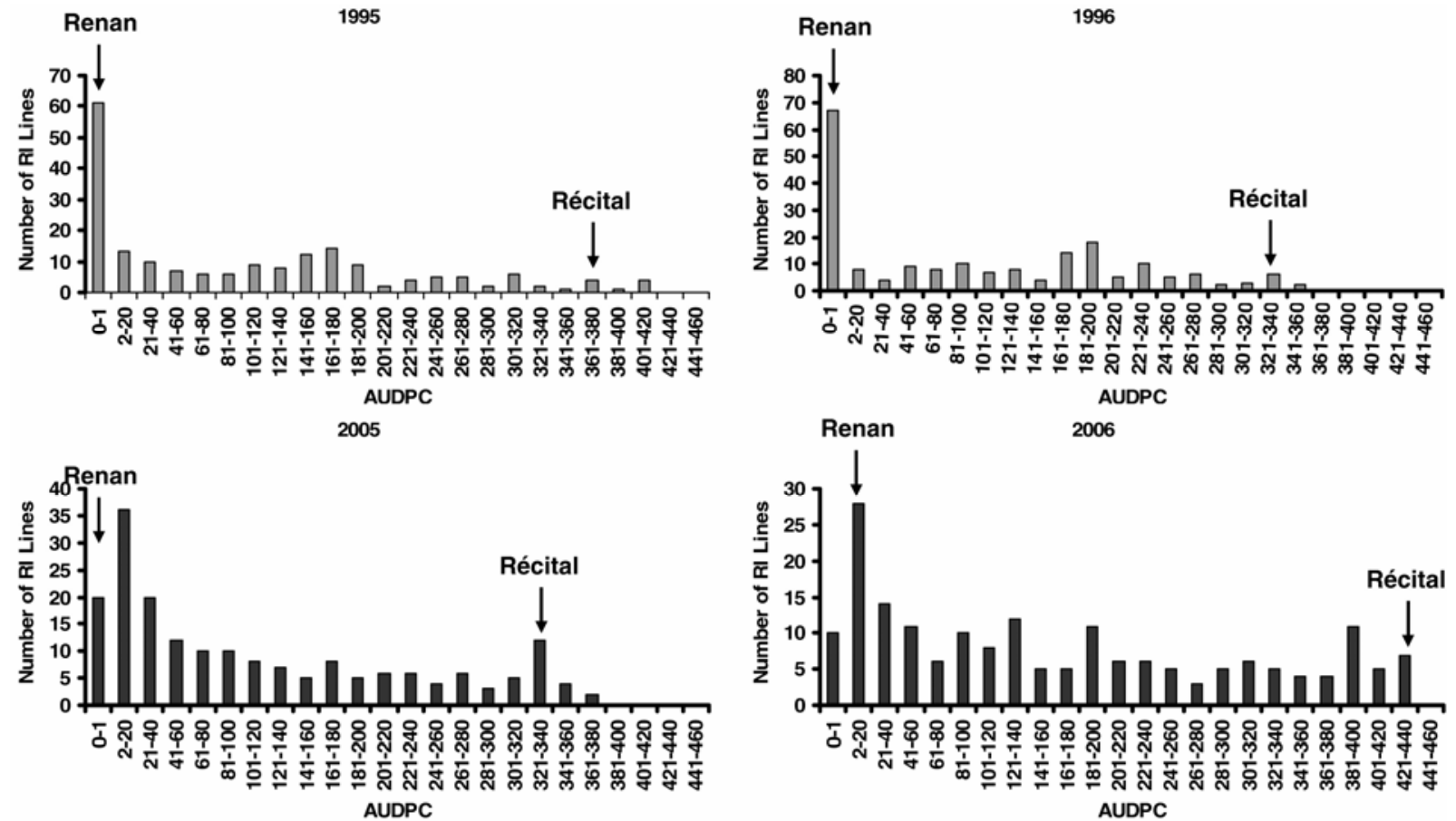

Fig. 1. Phenotypic distribution of stripe rust intensity area under the disease progress curve (AUDPC) for the 194 recombinant inbred lines (RILs) derived from the Renan $\times$ Récital cross in 1995, 1996, 2005, and 2006. The RILs were infected in 1995 and 1996 with the Puccinia striiformis f. sp. tritici 237E141 pathotype and with the 237E141 V17 pathotype in 2005 and 2006. The AUDPC values of the parental lines are indicated by arrows. 
plained 1.9 to $5.6 \%$ of the variance. In 2005 to 2006, one interaction was observed between QYrinra-6B and one locus, $X w m c 48$, not previously linked to any significant QTL. Interactions were observed between QTLs QYrinra-2BS-QYrinra$3 D S$ and QYrinra-2AS2-QYrinra-3BS. These interactions explained 2.8 to $3.5 \%$ of the variance. The combined additive and epistatic effects accounted for 98 and $74 \%$ of the total phenotypic variance observed in 1995 to 1996 and 2005 to 2006, respectively.

\section{DISCUSSION}

The present study confirmed the APR resistance of cv. Renan to stripe rust. AUDPCs for the Renan and Récital population had a continuous distribution (Fig. 1), suggesting a quantitative inheritance of the resistance. The parent Renan, which had a clearly compatible interaction with the 237E141 V17 pathotype at the seedling stage, remained highly resistant in the field in 2005 and 2006. Thus, we conclude that this cultivar carries valuable APR sources.

Our long-term goal is to understand the genetic basis of durable resistance to stripe rust. In this study, we identified stability and expression of different resistance QTL families. The QTL QYr.inra-2AS2, detected with the 237E141 pathotype (in 1995 to 1996) on the $A$. ventricosa introgression in Renan, was overcome in 2005 to 2006 by the 237E141 V17 pathotype, described as virulent against $\operatorname{Yrl7}(30)$. This suggests that the $\operatorname{Yrl7}$ gene in Renan corresponds to the QYrinra-2AS2 QTL, which was expressed in seedlings and adult plants in 1995 and 1996. The 2AS region in Récital which is homeologous to the A. ventricosa 10 introgression carries a minor QTL, QYrinra-2AS1, which conferred APR only in 2005 to 2006, when the V17 virulence pathotype was used in the experiments. The QYrinra- $B B S$, QYr.inra-3BS, and QYrinra-6B QTLs (Table 3; Fig. 2), derived from Renan, and the QYrinra-3DS QTL, derived from Récital, were stable over the 4 years. All the wheat lines carrying any one of these four QTLs gave clearly compatible interactions for both pathotypes used at the seedling stage but remained resistant in the field when challenged with the same virulent isolate. Thus, these lines appear to be carrying APRs (17) expressed at different adult plant stages. Different types of APR were detected in the Renan and Récital RILs. The lines carrying QYrinra-2BS and QYrinra$6 B$ were highly resistant at the N2 scoring but the resistance was expressed earlier for the first QTL (scoring N1) than for the second QTL (scoring N2). QYr.inra-3Bcent was only efficient early in growth, and detected in the first two scorings. In contrast, QYr.inra-3BS showed APR which was expressed at later stages of plant growth (scoring N3). The expressions of both QTLs were exclusive (Table 3; Fig. 2B) and probably depended upon the plant age and temperature increases during the growing season. The type of infection observed for the lines carrying the QYrinra$3 B S$ could indicate the presence of high-temperature adult plant (HTAP) resistance. In cultivars with only HTAP resistance, plants are more resistant and rust development slows or may even stop when the experimental temperature rises and as the plants grow older (7). The resistance conferred by QYrinra-3DS, linked to Récital alleles, was associated with a compatible interaction for all three scorings (N1, N2, and N3) and corresponds to slow rusting resistance. The total phenotypic variance explained by the QTLs was lower against the 237E141 V17 pathotype, when the resistance was only due to the action of APR genes, than in 1995 to 1996, when the pathotype used in the experiments was avirulent against $\operatorname{Yr} 17$. Eriksen et al. (13) showed that seedlingexpressed genes, such as $\mathrm{Yr} 17$, linked to the A. ventricosa introgression, tend to have more profound effects on the phenotype than APR genes.

The present study emphasized the importance of monitoring the progression of disease by scoring the disease reaction at more than one time during the growing season, as described by Ramburan et al. (29). Some QTLs were detected early in the field but others were identified only when final scores were taken into account. When a QTL was expressed at only one scoring stage and had a minor effect, it was not detected by the AUDPC QTL analysis (Table 3; Fig. 2B): for example, QYrinra-3BS, which was detected every year with the QTL analysis for scoring data, was never detected by AUDPC QTL analysis. The AUDPC measure has been used to integrate all aspects of disease progress in relation to host development and growth (18). The use of AUDPCs has been recommended for polycyclic foliar pathogens, when the shape of the disease-progress curve is sigmoid, and is particularly suitable for selecting slow-rusting genotypes (18). On the other hand, AUDPC is not adapted to detect QTLs expressed at only one plant developmental stage, such as HTPA-resistance QTLs.

Previous studies reported different loci for resistance to stripe rust in wheat. For example, QYrinra-3BS was mapped to the distal region of chromosome $3 \mathrm{~B}$ and this chromosomal region

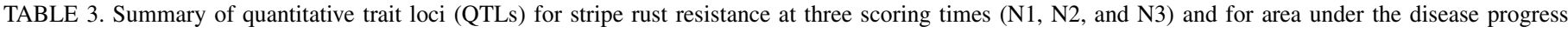
curve (AUDPC) and detected by composite interval mapping (CIM) in a Renan $\times$ Récital cross ${ }^{\mathrm{a}}$

\begin{tabular}{|c|c|c|c|c|c|c|c|c|c|c|}
\hline \multirow[b]{2}{*}{ Chromosome $^{b}$} & \multirow[b]{2}{*}{ Origin $^{c}$} & \multirow[b]{2}{*}{ Marker interval $^{\mathrm{d}}$} & \multicolumn{2}{|c|}{ N1 } & \multicolumn{2}{|c|}{ N2 } & \multicolumn{2}{|c|}{ N3 } & \multicolumn{2}{|c|}{ AUDPC } \\
\hline & & & LOD & $R^{2}$ & LOD & $R^{2}$ & LOD & $R^{2}$ & LOD & $R^{2}$ \\
\hline \multicolumn{11}{|c|}{ Mean 1995-1996 } \\
\hline 2AS2 & $\mathrm{Re}$ & $X S C A R$ & 27.97 & 39.65 & 35.61 & 42.80 & 19.95 & 18.78 & 35.68 & 44.49 \\
\hline $2 \mathrm{AL}$ & $\mathrm{Rc}$ & Xgwm382c-XBarc122 & 4.35 & 8.13 & 5.29 & 4.81 & 5.44 & 4.48 & 5.58 & 4.45 \\
\hline $2 \mathrm{BS}$ & $\operatorname{Re}$ & $X f b a 70-X f b b 67 c$ & 8.41 & 10.98 & 11.97 & 12.29 & 11.71 & 8.79 & 10.59 & 10.86 \\
\hline $3 \mathrm{BS}$ & $\operatorname{Re}$ & Xgwm533 & $\ldots$ & $\ldots$ & $\ldots$ & $\ldots$ & 4.14 & 3.32 & $\ldots$ & $\ldots$ \\
\hline 3DS & $\mathrm{Rc}$ & $X g w m 456-X g w m 55 b$ & 5.16 & 7.41 & 6.33 & 7.47 & 5.21 & 4.73 & 6.79 & 8.38 \\
\hline $6 \mathrm{~B}$ & $\mathrm{Re}$ & Xcdo270-Xgwm193 & $\ldots$ & $\ldots$ & 6.03 & 4.99 & 3.72 & 2.41 & 4.82 & 4.02 \\
\hline \multicolumn{11}{|c|}{ Mean 2005-2006 } \\
\hline $1 \mathrm{~A}$ & $\mathrm{Re}$ & Xfbal18b & $\ldots$ & $\ldots$ & $\ldots$ & $\ldots$ & 6.45 & 9.35 & $\ldots$ & $\ldots$ \\
\hline $2 \mathrm{AS} 1$ & $\mathrm{Rc}$ & XDupw210-Xcfd36 & $\ldots$ & $\ldots$ & 5.01 & 5.52 & 6.75 & 7.67 & 7.50 & 8.56 \\
\hline $2 \mathrm{BS}$ & $\mathrm{Re}$ & Xgwm210a-Xfbb67c & 4.59 & 6.70 & 10.32 & 12.82 & 12.94 & 16.48 & 11.10 & 13.03 \\
\hline $3 \mathrm{BS}$ & $\mathrm{Re}$ & Xgwm533 & $\ldots$ & $\ldots$ & $\ldots$ & $\ldots$ & 7.70 & 10.93 & $\ldots$ & $\ldots$ \\
\hline 3Bcent. & $\operatorname{Re}$ & Xgwm131b-Xbcd131 & 7.86 & 15.26 & 4.96 & 7.17 & $\ldots$ & $\ldots$ & 4.38 & 6.31 \\
\hline $3 \mathrm{DS}$ & $\mathrm{Rc}$ & XBarc125-Xgwm456a & 5.15 & 10.31 & 7.33 & 11.22 & 6.16 & 7.48 & 7.29 & 11.97 \\
\hline $6 \mathrm{~B}$ & $\mathrm{Re}$ & Xcdo270-Xgwm193 & $\ldots$ & $\ldots$ & 4.11 & 5.12 & 3.82 & 4.28 & 4.37 & 5.59 \\
\hline 7A & $\mathrm{Rc}$ & $X b c d 129 b-X f b a 127 c$ & 3.57 & 8.77 & $\ldots$ & $\ldots$ & $\ldots$ & $\ldots$ & $\ldots$ & $\ldots$ \\
\hline
\end{tabular}

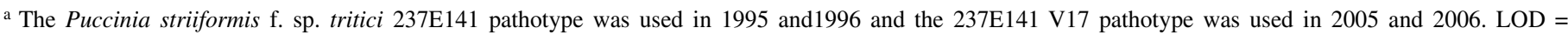
logarithm of odds and $R^{2}$ is the proportion of the phenotypic variance explained by the QTLs.

${ }^{\mathrm{b}}$ Chromosomal location of each QTL.

c Origin of resistance allele $(\mathrm{Re}=\mathrm{Renan}$ and $\mathrm{Rc}=$ Récital $)$.

d Markers in the QTL interval: peak position \pm 1 LOD. 
contains two stripe rust resistance genes: $\operatorname{Yr} 30$ (37), with minor effects on stripe rust resistance, and Yrns-Bl (5). The APR gene Yr30 has been deployed by CIMMYT to provide a durable resistance to stripe rust (35). Yrns-Bl is a major gene determining nonspecific resistance against stripe rust in adult plants, which has still not been overcome even though carriers of this gene have

A

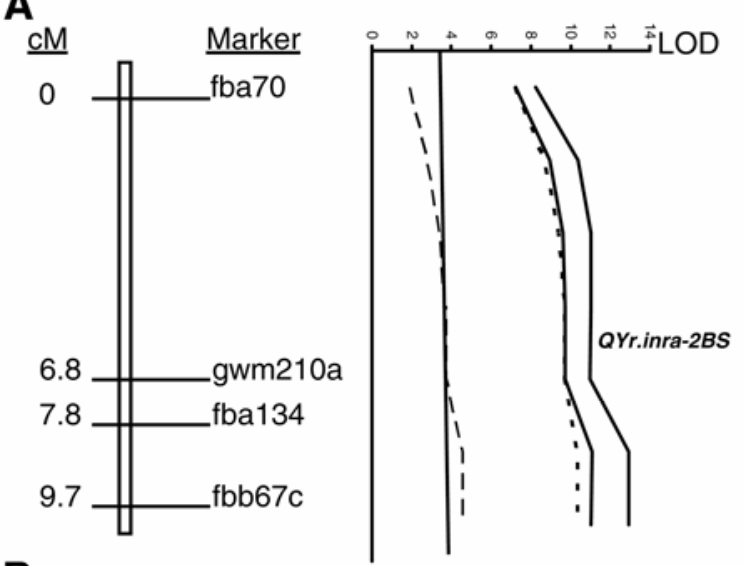

B

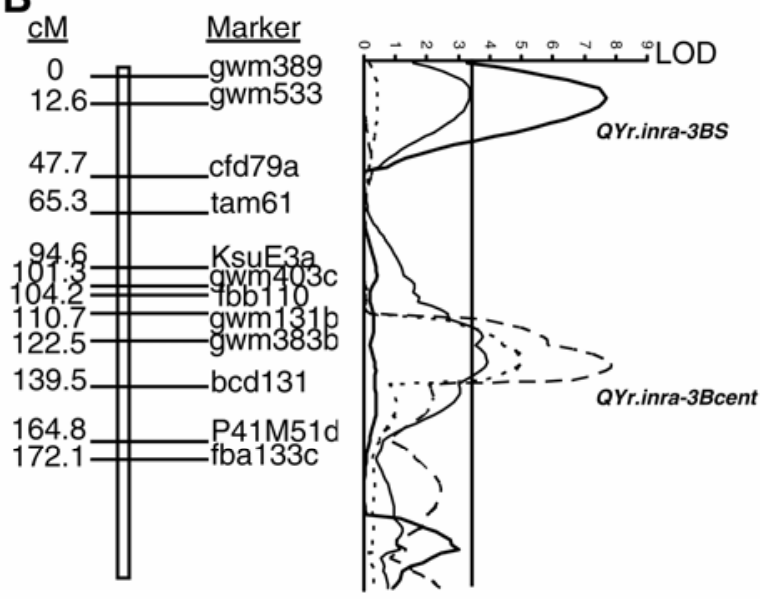

C

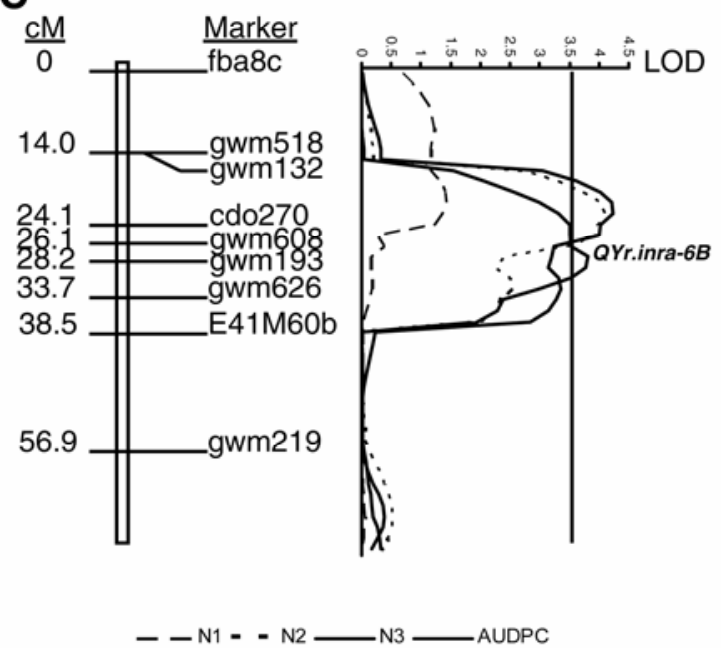

Fig. 2. Scan for stable Renan quantitative trait loci (QTLs) QYrinra-2BS, QYrinra-3BS, and QYrinra-6B detected in 2005-2006 with the Puccinia striiformis f. sp. tritici 237E141 V17 pathotype and mapped on linkage groups corresponding to chromosomes $\mathrm{A}, 2 \mathrm{BS} ; \mathrm{B}, 3 \mathrm{~B}$; and $\mathrm{C}, 6 \mathrm{~B}$ and using three scoring times $\mathrm{N} 1, \mathrm{~N} 2$, and $\mathrm{N} 3$ and area under the disease progress curve (AUDPC). The logarithm of odds (LOD) score scan was obtained by composite interval mapping using 10 cofactors. Vertical bold line indicated significant LOD thresholds (3.5) estimated from 1,000 permutations of the data. The positions of markers are shown along the chromosomes; $\mathrm{cM}=$ centimorgan. been grown throughout large areas for more than 100 years (22). This distal region of the 3BS chromosome was associated with stripe rust resistance genes implicated in this durable resistance. QYrinra-6B was identified in a region spanning $24.5 \mathrm{cM}$ on chromosome 6B, with $X c d o 270$ as the closest marker. An APR QTL for stripe rust $(9,37)$ and the HTAP resistance gene Yr36 from Triticum turgidum subsp. dicoccoides (38) were also detected in this same map interval. The effects from QYrinra- $2 B S$ conferred by Renan alleles on chromosome 2BS could be related to a stripe rust resistance QTL detected by Crossa et al. (10). One other resistance QTL, QYrinra-1A, with a resistance allele associated with the Renan allele, was unstable but could be related to known resistance QTLs against stripe rust. Ramburan et al. (29) identified an APR QTL on chromosome 1A, QYr.sgi-1A, which was also inconsistent depending on the test conditions. QYrinra$3 D S$ and $Q Y$ rinra-2AL, with alleles contributed by the susceptible parent Récital, are also in chromosomal regions where the presence of known stripe rust resistance genes and QTLs was previously described $(6,26,36)$. Finally, the chromosomal regions of QYrinra-2BS, QYrinra-3BS, and the Yrl7 introgression also corresponded to three of five regions where major resistance gene clusters were described by Dilbirligi et al. (12).

Durability is an important aspect in breeding wheat for stripe rust resistance. Adult plant resistance genes with partial and additive effects are currently favored by breeders because of their reputed durability (13). Breeding efforts to improve APR tend to be complicated by the small effect of individual APR genes and the difficulty of detecting them when major SR genes are present (38). A marker-assisted selection strategy can be used to accelerate the incorporation of these APR genes into adapted genotypes. As in Renan, a promising approach is to integrate QTLs associated with small effects or expressed at different stages in the development of the disease or under different environmental conditions (29) into new genotypes. Our results suggest that resistance against stripe rust of this type of cultivar would probably be durable: resistance could not be easily overcome by the rust pathogen because it would be confronted with different target genes at different infection cycles. Mallard et al. (27) showed that cv. Camp Rémy, another durable source of resistance to stripe rust, modifies some defense-related gene expression between two different infection cycles of the pathogen. In the Israeli wheat cv. Oligoculm, showing APR against stripe rust and proposed as a durable source of resistance, the combination of two QTLs found in the same chromosomal regions as QYrinra-3BS and QYrinra$6 B$ was implicated in the resistance (37). Renan also could be used as a source of stripe rust resistance for the generation of new wheat cultivars.

Yrl7-virulence is very common in northwestern-European $P$. striiformis f. tritici populations. However, $\mathrm{Yrl} 7$ resistance is also present in a huge number of cultivars and often combined with additional components of resistance, so that many cultivars remain resistant under field conditions even in the presence of widespread virulence for this gene (17). Chicaiza et al. (8) suggested that the presence of the $\operatorname{Yr} 17$ gene increased the slow rusting resistance to stripe rust conferred by $\operatorname{Yr} 18$ if these genes were introduced in the same genotype. Epistatic interactions between $\operatorname{Yr} 17$ (= QYrinra-2AS2) and some Renan QTLs were also observed in our study. Thus, the durability of resistance in Renan may be due to the combination of the race-specific resistance gene $\mathrm{Yr} 17$ and APR genes located on chromosomes 2B, 3B, and $6 \mathrm{~B}$ for which no stripe rust pathogen has yet evolved the necessary combination of virulence genes. Cultivar Kris, which is also resistant against stripe rust, presents a combination of resistance gene and QTL ( Yrl7 and a QTL detected on chromosome 6B) in common with Renan (9). By successfully tagging APR genes and QTLs with molecular markers, not only can their presence be identified but these could also be used in a pyramid approach with the $\operatorname{Yr} 17$ SR gene to generate new cultivars. 


\section{ACKNOWLEDGMENTS}

The mapping study was supported by the French ministers of Research and Agriculture and by private companies within the framework of a national plant genomics program, 'Génoplante'. Field evaluation was supported by GIE 'Club 5'. We thank C. De Vallavieille-Pope (INRA, UMR BIOGER, Grignon Research Centre) for providing the two pathogenic strains, F. Brunet for organizing field trials, and L. Gebbie for correcting the English.

\section{LITERATURE CITED}

1. Bariana, H. S., and McIntosh, R. A. 1994. Characterization and origin of rust and powdery mildew resistance genes in VPM1 wheat. Euphytica 76:53-61.

2. Basten, J. C., Weir, B. S., and Zeng, Z.-B. 2001. QTL Cartographer: A Reference Manual and Tutorial for QTL Mapping. North Carolina State University, Raleigh.

3. Bayles, R. A., Flath, K., Hovmøller, M. S., and de Vallavieille-Pope, C. 2000. Breakdown of the $\operatorname{Yr} 17$ resistance to yellow rust of wheat in northern Europe-a case study by the yellow sub-group of COST 817 . Agronomie 7:805-811.

4. Bayles, R. A., and Stigwood, P. 1994. UK cereal pathogen virulence survey 1994. Pages 16-21 in: Annual Report 1994. National Institute of Agricultural Botany, Cambridge.

5. Börner, A., Röder, M. S., Unger, O., and Meinel, A. 2000. The detection and molecular mapping of a major gene for non-specific adult-plant disease resistance against stripe rust (Puccinia striiformis) in wheat. Theor. Appl. Genet. 100:1095-1099.

6. Boukhatem, N., Baret, P. V., Mingeot, D., and Jacquemin, J. M. 2002. Quantitative trait loci for resistance against yellow rust in two wheatderived recombinant inbred line populations. Theor. Appl. Genet. 104:111-118

7. Chen, X. M. 2005. Epidemiology and control of stripe rust (Puccinia striiformis f. sp. tritici) on wheat. Can. J. Plant Pathol. 27:314-337.

8. Chicaiza, O., Khan, I. A., Zhang, X., Brevis, J. C., Jackson, L., Chen, X., and Dubcovsky, J. 2006. Registration of five wheat isogenic lines for leaf rust and stripe rust resistance genes. Crop Sci. 46:485-487.

9. Christiansen, M. J., Feenstra, B., Skovgaard, I. M., and Andersen, S. B. 2006. Genetic analysis of resistance to yellow rust in hexaploid wheat using a mixture model for multiple crosses. Theor. Appl. Genet. 112:581591.

10. Crossa, J., Burgueno, J., Dreisigacker, S., Vargas, M., Herrera-Foessel, S. A., Lillemo, M., Singh, R. P., Trethowan, R., Warburton, M., Franco, J., Reynolds, M., Crouch, J. H., and Ortiz, R. 2007. Association analysis of historical bread wheat germplasm using additive genetic covariance of relatives and population structure. Genetics 177:1889-1913.

11. De Vallavieille-Pope, C., Picard-Formery, H., Radulovic, S., and Johnson, R. 1990. Specific resistance factors to yellow rust in seedlings of some French wheat varieties and races of Puccinia striiformis Westend in France. Agronomie 2:103-113.

12. Dilbirligi, M., Erayman, M., Sandhu, M., Sidhu, D., and Gill, K. S. 2004. Identification of wheat chromosomal regions containing expressed resistance genes. Genetics 166:461-481.

13. Eriksen, L., Afshari, F., Christiansen, M. J., McIntosh, R. A., Jahoor, A., and Wellings, C. R. 2004. Yr32 for resistance to stripe (yellow) rust present in the wheat cultivar Carstens V. Theor. Appl. Genet. 108:567575.

14. Gervais, L., Dedryver, F., Morlais, J. Y., Bodusseau, V., Nègre, S., Bilous, M., Groos, C., and Trottet, M. 2003. Mapping of quantitative trait loci for field resistance to Fusarium head blight in an European winter wheat. Theor. Appl. Genet. 106:961-970.

15. Groos, C., Gay, G., Perretant, M. R., Gervais, L., Bernard, M., Dedryver, F., and Charmet, G. 2002. Study of the relationship between pre-harvest sprouting and grain color by quantitative trait loci in a whitexred grain bread-wheat cross. Theor. Appl. Genet. 104:39-47.

16. Haldane, J. B. S. 1919. The combination of linkage values, and the calculation of distances between loci of linked factors. J. Genet. 8:299309.

17. Hovmøller, M. S. 2007. Sources of seedling and adult plant resistance to Puccinia striiformis f. sp. tritici in European wheats. Plant Breed. $126: 225-233$

18. Jeger, M. J., and Viljanen-Rollinson, S. L. H. 2001. The use of the area under the disease-progress curve (AUDPC) to assess quantitative disease resistance in crop cultivars. Theor. Appl. Genet. 102:32-40.
19. Johnson, R. 1981. Durable resistance: definition, genetic control, and attainment in plant breeding. Phytopathology 71:567-568.

20. Johnson, R. 1984. A critical analysis of durable resistance. Annu. Rev. Phytopathol. 22:309-330.

21. Johnson, R. 1992. Past, present and future opportunities in breeding for disease resistance, with examples from wheat. Euphytica 63:3-22.

22. Khlestkina, E. K., Röder, M. S., Unger, O., Meinel, A., and Börner, A. 2007. More precise map position and origin of a durable non-specific adult plant disease resistance against stripe rust (Puccinia striiformis) in wheat. Euphytica 153:1-10.

23. Lander, E. S., and Bolstein, D. 1989. Mapping Mendelian factors underlying quantitative traits using RFLP linkage maps. Genetics 121:185-199.

24. Lincoln, S. E., Daly, M. J., and Lander, E. S. 1992. Constructing Genetic Maps with MAPMAKER/EXP ver. 3.0, 3rd ed. Whitehead Institute Technical Report, Cambridge, MA.

25. Maia, N. 1967. Obtention de blés tendres résistants au piétin-verse (Cercosporella herpotrichoides) par croisements interspécifiques. C. R. Acad. Sci. 53:149-154.

26. Mallard, S., Gaudet, D., Aldeia, A., Abelard, C., Besnard, A. L., Sourdille, P., and Dedryver, F. 2005. Genetic analysis of durable resistance to yellow rust in bread wheat. Theor. Appl. Genet. 110:1401-1409.

27. Mallard, S., Nègre, S., Pouya, S., Gaudet, D., Lu, Z.-X., and Dedryver, F. 2008. Adult plant resistance-related gene expression in 'Camp Remy' wheat inoculated with Puccinia striiformis. Mol. Plant Pathol. 9:213-225.

28. McIntosh, R. A., Yamazaki, Y., Dubcovsky, J., Rogers, J., Morris, C., Somers, D. J., Appels, R., and Devos, K. M. 2008. Catalogue of gene symbols for wheat-morphological and physiological traits. In: Proc. 11th Int. Wheat Genet. Symp. Brisbane, Australia.

29. Ramburan, V. P., Pretorius, Z. A., Louw, J. H., Boyd, L. A., Smith, P. H., Boshoff, W. H. P., and Prins, R. 2004. A genetic analysis of adult plant resistance to stripe rust in the wheat cultivar Kariega. Theor. Appl. Genet. 108:1426-1433.

30. Robert, O. 1998. Etude et marquage moléculaire de gènes de résistance à la rouille jaune du blé présents chez des variétés issues de VPM. Thèse de doctorat, Ecole Nationale Supérieure Agronomique, Rennes, France.

31. Robert, O., Abelard, C., and Dedryver, F. 1999. Identification of molecular marker for the detection of the yellow rust resistance gene $\mathrm{Yr} 17$ in the wheat. Mol. Breed. 5:167-175.

32. Robert, O., Dedryver, F., Leconte, M., Rolland, B., and De VallavieillePope, C. 2000. Combination of resistance tests and molecular tests to postulate the yellow rust resistance gene $\mathrm{Yr} 17$ in bread wheat lines. Plant Breed. 119:467-472.

33. Röder, M. S., Korzun, V., Wendehake, K., Plaschke, J., Tixier, M. H., Leroy, P., and Ganal, M. W. 1998. A microsatellite map of wheat. Genetics 149:2007-2023.

34. Rogers, S. O., and Bendich, A. J. 1985. Extraction of DNA from milligram amounts of fresh, herbarium and mummified plant tissues. Plant Mol. Biol. 5:69-76.

35. Singh, R. P., Huerta-Espino, J., and William, H. M. 2005. Genetics and breeding for durable resistance to leaf and stripe rusts in wheat. Turk. J. Agric. For. 29:121-127.

36. Singh, R. P., Nelson, J. C., and Sorells, M. E. 2000. Mapping Yr28 and other genes for resistance to stripe rust in wheat. Crop Sci. 40:1148-1155.

37. Suenaga, K., Singh, R. P., Huerta-Espino, J., and William, H. M. 2003. Microsatellite markers for genes $\operatorname{Lr} 34 / \mathrm{Yr} 18$ and other quantitative trait loci for leaf rust and stripe rust resistance in bread wheat. Phytopathology 93:881-890

38. Uauy, C., Brevis, J. C., Chen, X., Khan, I., Jackson, L., Chicaiza, O., Distelfeld, A., Fahima, T., and Dubcovsky, J. 2005. High-temperature adult-plant (HTAP) stripe rust resistance gene Yr36 from Triticum turgidum ssp. dicoccoides is closely linked to the grain protein content locus $G p c-B 1$. Theor. Appl. Genet. 112:97-105.

39. Vos, P., Hogers, R., Bleeker, M., Reijans, M., Van de Lee, T., Hornes, M., Frijters, A., Pot, J., Peleman, J., Kuiper, M., and Zabeau, M. 1995. AFLP: a new technique for DNA fingerprinting. Nucleic Acids Res. 23:44074414.

40. Zadoks, J. C. 1961. Yellow rust on wheat: Studies in epidemiology and physiologic specialisation. Tijdschr. Plantenziekten 67:69-256.

41. Zadoks, J. C., Chang, T. T., and Konzak, C. F. 1974. A decimal code for the growth stages of cereals. Weed Res. 14:415-421.

42. Zeng, Z. B. 1993. Theoretical basis for separation of multiple linked gene effects in mapping quantitative trait loci. Proc. Natl. Acad. Sci. USA 90:10972-10976.

43. Zeng, Z. B. 1994. Precision mapping of quantitative trait loci. Genetics 136:1457-1468. 